\title{
Hydrodynamic Suppression of Soot Emissions in Laminar Diffusion Flames
}

\author{
K.-C. Lin* and G. M. Faeth $\dagger$ \\ University of Michigan, Ann Arbor, Michigan 48109-2118
}

\begin{abstract}
Effects of flow (hydrodynamic) properties on soot formation and oxidation in nonpremixed hydrocarbon/air flames were studied, emphasizing conditions where effects of buoyancy are small in coflowing laminar jet diffusion flames. Effects of air/fuel-stream velocity ratios were of particular interest; therefore, the experiments were carried out at reduced pressures (0.19-0.50 atm) in order to minimize effects of flow acceleration due to buoyancy. Test conditions included acetylene, propylene, and 1,3-butadiene flames burning in air with air/fuel-stream velocity ratios in the range 0.4-6.7. Measurements included laminar smoke-point properties, as well as the following flame structure properties: soot volume fractions, temperatures, soot structure, concentrations of major gas species, and velocities. The measurements showed that laminar smoke-point flame lengths can be increased, and soot emissions possibly suppressed entirely, by increasing air/fuel-stream velocity ratios. The flame structure measurements suggest that the mechanism of this effect involves the magnitude and direction of flow velocities relative to the flame sheet. In particular, large air/fuel-stream velocity ratios cause soot to form in cool and fuel-rich gases, inhibiting soot nucleation, and then to be drawn directly toward the flame sheet with a limited residence time, inhibiting soot growth, so that capabilities to complete the oxidation of soot are enhanced and the tendencies to emit soot are reduced.
\end{abstract}

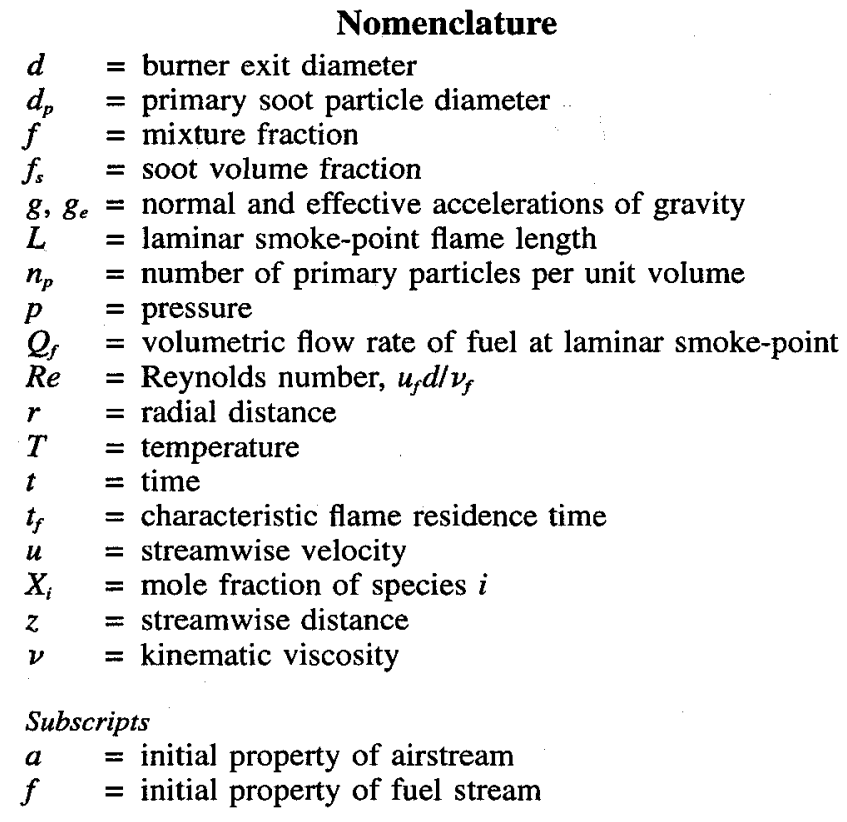

\section{Introduction}

$T \mathrm{~T}$ is widely understood that soot can be controlled in typical nonpremixed hydrocarbon combustor configurations by rapid turbulent mixing. ${ }^{1-3}$ This approach has evolved empirically, based on the idea that fuel residence times at fuel-rich conditions should be kept small so that the soot particles only grow to a limited extent and can be readily consumed in the soot oxidation regions of the flame. The overall objective of

Received Jan. 15, 1994; presented as Paper 95-0375 at the AIAA 33rd Aerospace Sciences Meeting and Exhibit, Reno, NV, Jan. 9-12, 1995; revision received June 30,1995; accepted for publication July 21, 1995. Copyright (C) 1995 by the American Institute of Aeronautics and Astronautics, Inc. All rights reserved.

*Graduate Student Research Assistant, Department of Aerospace Engineering.

$†$ Professor, Department of Aerospace Engineering. Fellow AIAA. the present investigation is to show that this interpretation is somewhat incomplete because the mechanism of the fast turbulent mixing also is important, and to suggest that a better understanding of aspects of contemporary methods of promoting turbulent mixing will lead to more effective methods of soot control that will be needed to meet future soot emissions requirements.

While it is certainly true that fast mixing helps to control soot in diffusion flames, because premixed flames are a limiting condition of this process and provide a well-known method to control soot, ${ }^{1-3}$ the way that mixing is carried out is crucial as well. In fact, existing evidence from both turbulent and laminar jet diffusion flames, and from empirical industrial practice, suggests that soot reductions in nonpremixed flames can be achieved most effectively by ensuring that the fuelstream velocity is smaller than the airstream velocity, i.e., that the fuel-stream velocity is retarded.

Turbulent nonpremixed jet flames with enhanced fuel-stream velocities have been widely studied as models of practical combustion processes. Supporting the short residence-time hypothesis, measurements of fully developed turbulent jet diffusion flames generally show that soot emissions are reduced when the fuel-stream velocity is increased. However, measurements of soot concentrations within the fuel-rich regions of nonpremixed turbulent jet flames having enhanced fuelstream velocities show that they are relatively insensitive to fuel-stream velocity variations (residence times), except at very short residence times as blowoff conditions are approached. ${ }^{4}$ Thus, large fuel-stream velocities alone do not provide a complete approach to control soot in view of the operational limitations of practical combustors.

Problems of measuring soot properties in turbulent flames, due to unsteadiness and limited spatial resolution, have prompted studies of nonpremixed laminar flames that are more accessible for measurements: Coflowing laminar jet diffusion flames, with the fuel stream along the axis, have been studied most frequently as the counterpart of turbulent jet diffusion flames (see Refs. 5-10 and references cited therein). Due to low burner exit velocities, these flames are strongly influenced by buoyancy so that the configuration is representative of enhanced fuel-stream velocities for the range of velocities at the 
burner exit that generally is considered. Studies of these flames show that soot largely is confined to a narrow region (soot layer) just on the fuel-rich side of the flame sheet, except near the tip of the flame where the soot layer crosses the flame sheet. Additionally, maximum soot concentrations in the soot layer are similar to those observed in the fuel-rich region of turbulent diffusion flames having enhanced fuel-stream velocities, helping to support the use of laminar flames as a reasonable model of practical turbulent flames. ${ }^{11-13}$

The measurements of $\mathrm{Wu}$ and Essenhigh ${ }^{14}$ are illuminating in view of the correspondence between laminar and turbulent diffusion flames. These investigators reversed the fuel and air ports of laminar coflowing jet diffusion flames, placing the airstream along the axis. Due to effects of buoyancy, this configuration corresponds to retarded fuel-stream velocities. The result was barely perceptible thin soot layers along most of the flame surface, with much reduced soot concentrations, in comparison to the conventional configuration where the airstream velocity is retarded. Thus, in this instance, retarded fuel-stream velocities acted to reduce soot concentrations for flame residence times that yield significant soot concentrations for retarded airstream velocities.

A possible reason for the strong effect of the ratio of air/ fuel-stream velocities on soot concentrations in nonpremixed flames is provided by the hydrodynamics of the flow as sketched in Fig. 1. To simplify the discussion, the configuration considered in Fig. 1 involves a nonbuoyant coflowing jet diffusion flame having uniform initial air and fuel velocities at the base of the flame, $u_{a}$ and $u_{f}$, respectively. First of all, because of their size, soot particles do not diffuse like gas molecules; instead, they are convected at the velocity of the flow modified slightly by effects of thermophoresis. ${ }^{7,8}$ Then, for enhanced fuel-stream velocities, entrainment induced by the higher velocity fuel stream causes streamlines to cross the flame toward the fuel side. As a result, soot particles forming on the fuel-rich side of the flame are convected away from the flame surface, yielding long residence times at fuel-rich conditions so that the particle growth is enhanced. This implies large soot particles within the soot layer when the flame tip is reached; naturally, such large soot particles are difficult to oxidize completely in the fuel-lean regions of the flame, so that the potential for soot emissions is relatively high. In contrast, when the fuel-stream velocity is retarded, entrainment from the higher-speed airstream causes streamlines to cross the flame toward the air side. This implies that soot particles forming just on the fuel-rich side of the flame sheet are drawn immediately into the oxidation zone where they are readily oxidized because they have had little time to grow in the fuelrich region. Thus, for similar residence times for the combustion process as a whole, retarded fuel-stream velocities intrinsically reduce residence times for the soot growth process, in comparison to conditions where airstream velocities are retarded.

Additional evidence for the importance of retarded fuelstream velocities for soot processes comes from practical turbulent flame systems, such as the Meurer diesel engine system and the widespread use of air-assist atomization for reducing soot in air-breathing jet propulsion engines. The Meurer diesel engine combustion system involves spraying fuel as a sheet on the combustion chamber walls. ${ }^{2}$ The fuel evaporates from this slowly moving liquid layer into a high-speed airflow, yielding a retarded fuel-stream velocity. This arrangement results in well-documented reductions of the tendency to soot of the combustion process, even in comparison to hypervelocity fuel sprays yielding fine atomization and rapid mixing. Hussman and Mayback ${ }^{15}$ applied the Meurer concept to gas-turbine combustors, finding remarkable capabilities to burn normally heavily sooting fuels as blue flames having negligible soot concentrations. Although the authors attributed soot control to rapid turbulent mixing, the configuration had roughly the same mixing rates as other combustor designs of that time; rather,

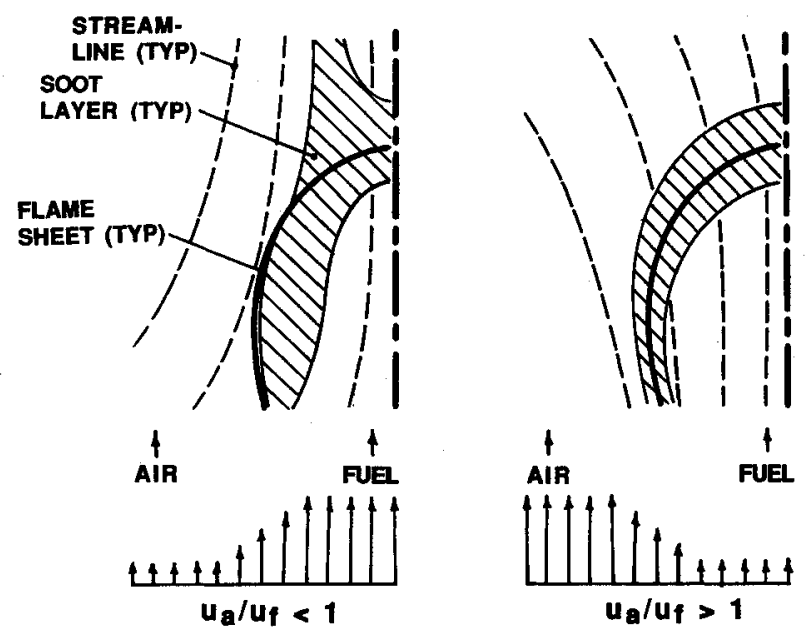

Fig. 1 Effect of reactant-stream velocities on soot properties in nonbuoyant laminar jet diffusion flames having uniform initial air and fuel velocities, $u_{a}$ and $u_{f}$, at the base of the flames.

the retarded fuel-stream velocity was probably the most critical factor for reducing soot emissions.

Air-assist atomization is widely used for soot control in aircraft gas turbine combustors. ${ }^{3}$ The reduced soot levels provided by air-assist atomization generally are.thought to be due to better atomization and faster mixing rates; however, this is not sufficient to explain the effect completely. For example, even gaseous fuels, which represent the best possible atomization performance, exhibit excessive soot concentrations for enhanced fuel-stream velocities having comparable residence times. A more promising explanation follows by noting that air-assist atomization intrinsically involves retarded fuelstream velocities, somewhat analogous to the Meurer concept. Thus, more knowledge about the effects of retarded fuelstream velocities on soot processes in diffusion flames has the potential of providing improved understanding of soot control by air-assist atomization.

Finally, recent papers by Sugiyama ${ }^{16}$ and Du and Axelbaum $^{17}$ also highlight the importance of the direction of soot motion with respect to the flame sheet on the soot properties of diffusion flames. Both of these studies consider methods of modifying soot motion by changing the composition of the reactant streams rather than their velocities. Sugiyama ${ }^{16}$ considered soot formation in a coflowing jet diffusion flame and showed that if the soot particles were made to cross the flame sheet directly from rich to lean conditions, by diluting the fuel stream with nitrogen and increasing the oxygen concentration of the oxidizer stream, soot concentrations were reduced (as evidenced by increased ranges of operation where the flames were blue). Du and Axelbaum ${ }^{17}$ observed similar behavior in opposed jet diffusion flames, where stoichiometries that cause soot to convect directly from fuel-rich to fuel-lean conditions also reduced the strain rates required to eliminate the appearance of soot entirely. These promising observations provide strong motivation to determine whether large air/fuel-stream velocity ratios, which represents a more practical approach for industrial use to control soot, promote similar behavior.

To summarize, the soot control mechanism vaguely attributed to fast turbulent mixing appears to involve retarded fuelstream velocities as a dominant feature. Present understanding of this mechanism is not very complete; in fact, reasons given for current industrial practice to control soot are not very plausible based on existing measurements in the literature. Thus, the goal of the present investigation is to undertake an experimental study of soot properties in nonpremixed flames, emphasizing the role of reactant-stream velocities, in order to determine whether retarded fuel-stream velocities are beneficial for controlling soot for practical nonpremixed combustion systems. The specific objectives of the study are as follows: 
1) The first objective is to complete measurements of the laminar smoke-point flame lengths of weakly buoyant coflowing laminar jet diffusion flames burning in air, emphasizing a range of reactant-stream velocity ratios and fuel types.

2) The second objective is to complete detailed measurements of the soot and flame structure properties of weakly buoyant coflowing laminar jet diffusion flames, in order to gain insight about the effects of reactant-stream velocities on soot processes within nonpremixed flames.

Laminar smoke-point flame lengths were used as a reasonably direct measure of the sooting properties of fuels, similar to past work by Schug et al. ${ }^{18}$ and others. ${ }^{19}$ Since the determination of laminar smoke-points involves the use of coflowing laminar jet diffusion flames, the same flame geometry was used for the more detailed measurements of soot properties and flame structure. These structure measurements exploited techniques recently developed in this laboratory during studies of soot processes in laminar diffusion flames. ${ }^{20-22}$ Effects of fuel type were investigated for hydrocarbon fuels having relatively low $\mathrm{H} / \mathrm{C}$ ratios, including acetylene, propylene, and 1,3-butadiene.

In the following, experimental methods are described first, then the results are discussed, considering laminar smokepoints and flame structure, in turn.

\section{Experimental Methods}

\section{Apparatus}

Effects of buoyancy must be controlled during laminar flame experiments to obtain a proper simulation of practical turbulent flames where effects of buoyancy generally are negligible. This problem was approached based on the observation that the governing equations for laminar coflowing jet diffusion flames scale with pressure to yield an effective gravitational acceleration, $g_{e}=p^{2} g$ with $p$ in atm. ${ }^{23}$ Thus, flames at pressures on the order of 0.1 atm have effective gravitational accelerations on the order of $10^{-2} \mathrm{~g}$ and exhibit relatively weak effects of buoyancy for typical burner exit velocities at modest distances from the burner exit.

A sketch of the test apparatus appears in Fig. 2. The burner is a coaxial tube arrangement with the fuel flowing from the inner port ( $6 \mathrm{~mm}$ diameter) and air flowing from the outer port (60 mm diameter). The outer port involves several layers of beads and screens to provide a uniform velocity distribution at the burner exit while the inner port involves fully developed laminar pipe flow at the burner exit. The entire burner assembly can be traversed in the vertical and horizontal directions using stepping-motor driven linear positioners.

The burner assembly operates at low pressures within a windowed chamber. Fuel is supplied from commercial cylinders and is controlled and metered by pressure regulators and rotameters. Air is supplied directly from the room, with critical flow orifices used to control and meter flow rates. Exhaust products pass through a porous plate in order to help maintain uniform flow conditions within the chamber. After air dilution to reduce flow temperatures, the exhaust flow is removed using the laboratory vacuum supply. Optical access is provided by two pairs of opposing windows, all centered on the same horizontal plane and having $100 \mathrm{~mm}$ diameters. The flames are ignited by a hot wire that can be manually moved out of the flowfield once the flames are ignited and stabilized.

\section{Instrumentation}

In addition to measurements of luminous flame lengths by photography, which were needed to define laminar smokepoint properties, detailed measurements of flame structure were undertaken to determine the effect of air/fuel-stream velocity ratios on the sooting properties of laminar diffusion flames. These structure measurements included soot volume fractions, temperatures, soot structure, gas compositions, and gas velocities.

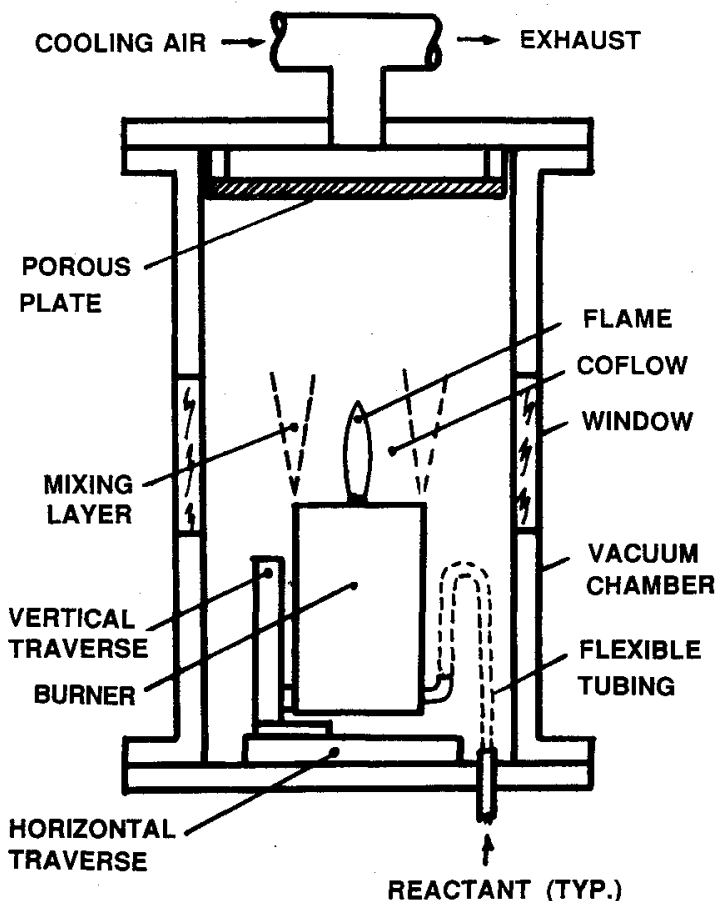

Fig. 2 Sketch of the laminar diffusion flame apparatus.

Soot volume fractions were measured by deconvoluting laser extinction measurements for chord-like paths through the flames, similar to past work. ${ }^{20-22}$ The data were reduced assuming that soot optical properties satisfied the small-particle (Rayleigh) scattering limit. ${ }^{24}$ Refractive indices were taken from Dalzell and Sarofim, ${ }^{25}$ similar to past work, ${ }^{20-22}$ as justified by recent in situ measurements in buoyant diffusion flames. ${ }^{26}$ Experimental uncertainties of these measurements ( $95 \%$ confidence) are estimated to be less than $10 \%$ for $f_{s}>$ $0.1 \mathrm{ppm}$.

Temperatures were measured in regions where soot was present using multiline emission. The multiline emission measurements were identical to Refs. 20-22 and involved deconvoluting spectral radiation intensity measurements for chordlike paths through the flames. The temperatures were found from measurements at three line pairs; namely, 600/750, 700/ 830 , and $600 / 830 \mathrm{~nm}$. Temperature differences between the average and any of the line pairs were less than $30 \mathrm{~K}$ while experimental uncertainties ( $95 \%$ confidence) of these measurements are estimated to be less than $50 \mathrm{~K}$.

Soot structure was measured using thermophoretic sampling and analysis by TEM, similar to earlier work. ${ }^{20-22}$ Effects of soot aggregate size causes a negligible sampling bias for present test conditions. ${ }^{26,27}$ As usual, soot consisted of nearly spherical and monodisperse primary particles (standard deviation less than $20 \%$ ), collected into aggregates having widely varying numbers of primary particles. Primary particle diameters were measured for more than 60 particles to yield experimental uncertainties ( $95 \%$ confidence) for $d_{p}$ less than $10 \%$. The number of primary soot particles per unit volume was then found from the other measurements, as follows:

$$
n_{p}=6 f_{s} /\left(\pi d_{p}^{3}\right)
$$

In view of the experimental uncertainties for $f_{s}$ and $d_{p}$, Eq. (1) implies experimental uncertainties ( $95 \%$ confidence) for $n_{p}$ less than $32 \%$ for $f_{s}>0.1 \mathrm{ppm}$.

Gas compositions were measured by sampling and analysis using gas chromatography, similar to past work. ${ }^{20-22}$ A stainless-steel radiatively cooled sampling probe was used, having a port diameter of $2.1 \mathrm{~mm}$. Gas species resolved by the analysis included $\mathrm{N}_{2}, \mathrm{O}_{2}, \mathrm{CO}_{2}, \mathrm{CO}, \mathrm{H}_{2} \mathrm{O}, \mathrm{H}_{2}, \mathrm{CH}_{4}, \mathrm{C}_{2} \mathrm{H}_{2}, \mathrm{C}_{2} \mathrm{H}_{4}$, 
$\mathrm{C}_{2} \mathrm{H}_{6}$, and $\mathrm{C}_{3} \mathrm{H}_{8}$. Experimental uncertainties (95\% confidence) of these measurements generally were less than $15 \%$ for mole fractions greater than $100 \mathrm{ppm}$, dominated by the uncertainties of measuring peak areas on the chromatographs.

Velocities were measured using laser velocimetry based on a dual-beam forward-scatter arrangement, with the flow seeded with aluminum oxide particles, similar to past work. ${ }^{20-22}$ The streamwise and cross-stream velocities were measured in a plane through the flame axis by rotating the laser velocimeter optics accordingly. Experimental uncertainties (95\% confidence) of the velocity components were as follows: uncertainties of the streamwise components generally were less than $5 \%$, dominated by calibration uncertainties; and minimum uncertainties of cross-stream components generally were less than $15 \%$, dominated by sampling limitations, with the larger uncertainties of this component resulting because cross-stream velocities are much smaller than streamwise velocities.

\section{Results and Discussion}

\section{Laminar Smoke-Points}

Similar to the observations of Glassman and co-workers, ${ }^{18}$ luminous flame lengths at the laminar smoke points (the condition where soot begins to be emitted from the flame), were closely associated with the fuel flow rate. This behavior is illustrated in Fig. 3 where the laminar smoke-point flame length is plotted as a function of the fuel flow rate. These results are for acetylene, propylene, and 1,3-butadiene flames burning in still air at pressures in the range 0.19-0.50 atm and various air/fuel-stream velocity ratios for the present test burner. The results indicate a good correlation between $L$ and $Q_{f}$ at the laminar smoke-point for each fuel, even though the values of $L$ vary substantially with pressure and air/fuel-velocity ratio. As a result, the laminar smoke-point condition will be represented by the laminar smoke-point fuel flow rate alone, in the following.

Effects of air/fuel-stream velocity ratios were qualitatively similar for the three fuels considered: acetylene, propylene, and 1,3-butadiene. This can be seen from the plots of $Q_{f}$ as a function of $u_{a} / u_{f}$ for various pressures illustrated in Figs. 46 . Increasing $u_{a} / u_{f}$ clearly increases $Q_{f}$, with this effect being most evident at low pressures where effects of buoyancy are minimized and velocity ratios over the length of the flames tend to change the least from the initial velocity ratios. Thus, sufficiently large air/fuel-stream velocity ratios are capable of completely suppressing soot emissions at these conditions, supporting the soot suppression argument discussed in connection with Fig. 1. The reduced effect of air/fuel-stream velocity ratio on $Q_{f}$ as the pressure increases is due to effects of buoyancy, because $u_{a} / u_{f}$ is no longer representative of velocity

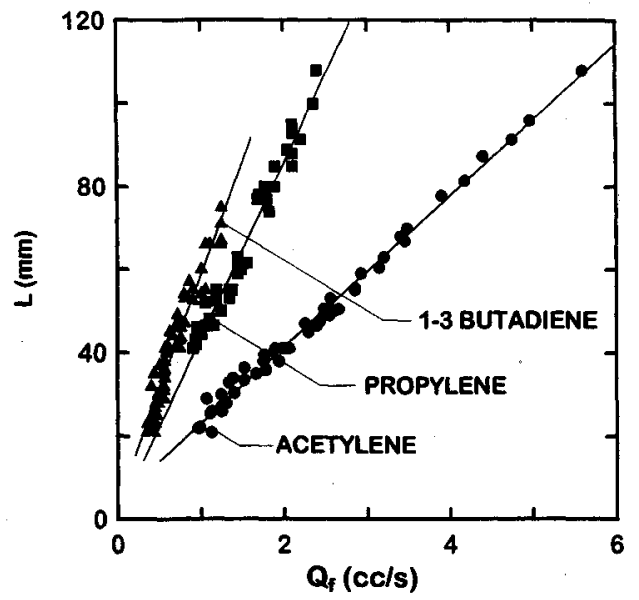

Fig. 3 Correlation between fuel flow rates and laminar smokepoint flame lengths for acetylene, propylene, and 1,3-butadiene flames burning in air.

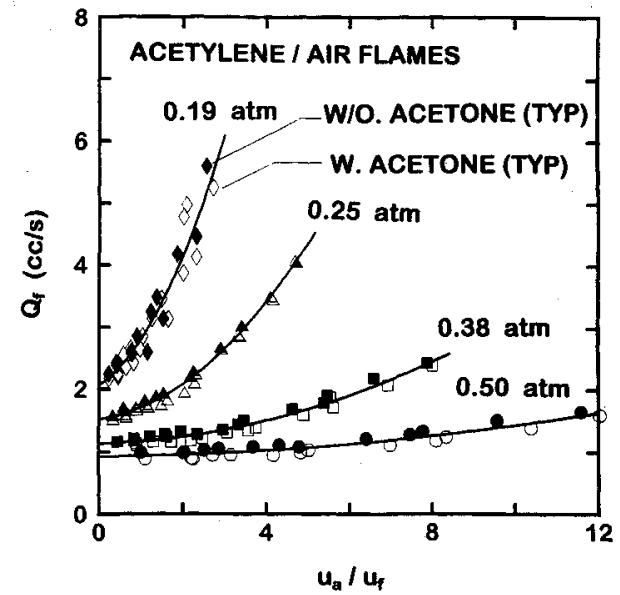

Fig. 4 Laminar smoke-point fuel flow rates as a function of air/ fuel velocity ratios for acetylene/air flames.

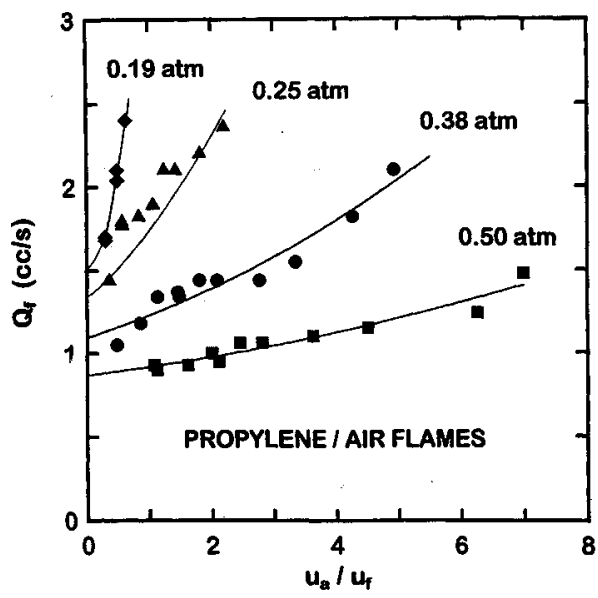

Fig. 5 Laminar smoke-point fuel flow rates as a function of air/ fuel velocity ratio for propylene/air flames.

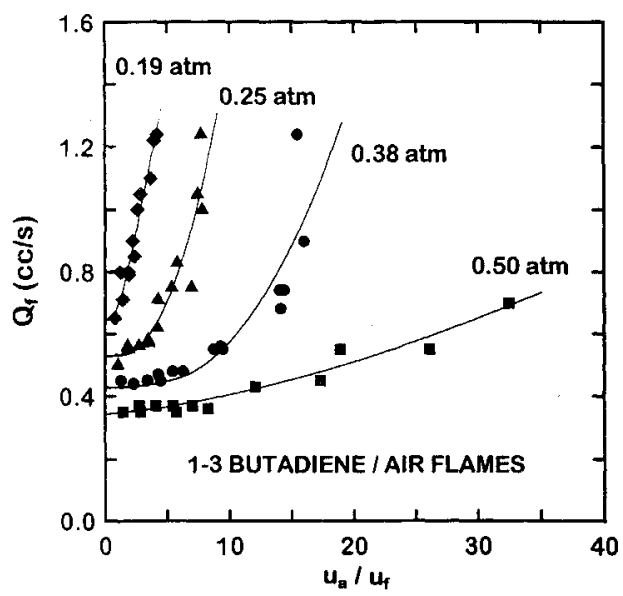

Fig. 6 Laminar smoke-point fuel flow rates as a function of air/ fuel velocity ratio for 1,3-butadiene flames.

ratios over most of the flame due to buoyant acceleration of the heated region near the flame sheet discussed earlier. This behavior has made it difficult to recognize the effect of reactant-stream velocity ratios on soot processes in laminar jet diffusion flames because most past observations have been carried out at normal gravity and atmospheric pressure. ${ }^{18}$

For safety purposes, acetylene generally is stored in contact with acetone; therefore, contamination of acetylene with acetone can be a problem by affecting soot formation proper- 
Table 1 Summary of the test flames"

\begin{tabular}{lrrr}
\hline \hline Test flames & \multicolumn{1}{c}{2} & \multicolumn{1}{c}{3} \\
\hline Air/fuel velocity ratio & 1.3 & 3.4 & 6.3 \\
Air flow rate, cm ${ }^{3} / \mathrm{s}$ & 2,100 & 5,460 & 10,100 \\
Air velocity, mm/s & 750 & 1,950 & 3,610 \\
Laminar flame length, mm & 63 & 50 & 43 \\
Stoichiometric flame length, mm & 77 & 60 & 53 \\
Char. residence time, ms & 34 & 19 & 12 \\
\hline \hline
\end{tabular}

"Laminar coflowing jet diffusion flames with a 6-mm-i.d. fuel port, surrounded by a $60-\mathrm{mm}$-i.d. air port, operating at $19 \mathrm{kPa}$. Acetylene fuel flow rate of 3.85 $\mathrm{cm}^{3} / \mathrm{s}$ with a fuel velocity of $575 \mathrm{~mm} / \mathrm{s}$ and a fuel port Reynolds number of $9.3 \times 10^{6}$ (the last two parameters are based on a nominal temperature of 298 $\pm 2 \mathrm{~K})$.

${ }^{5}$ Nominal average value based on an injector temperature of $298 \pm 2 \mathrm{~K}$.

a)

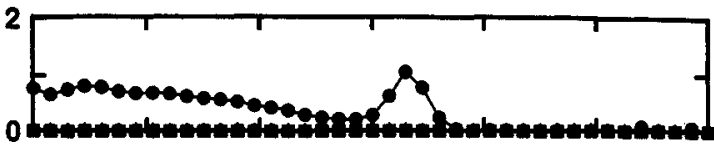

b)

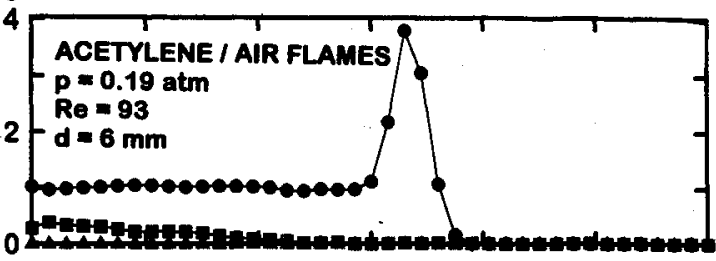

d)

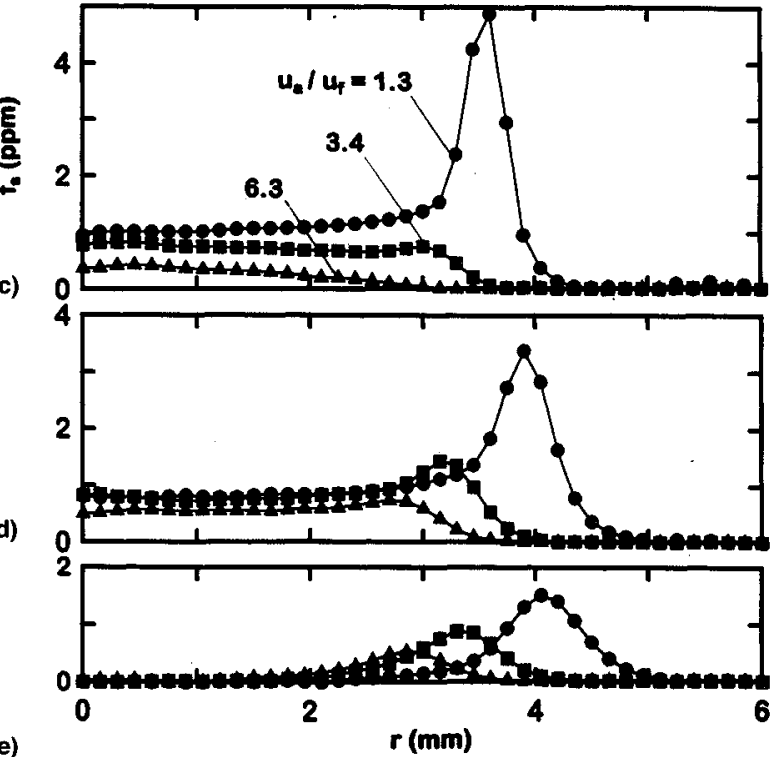

e)

$r(\mathbf{m m})$

Fig. 7 Soot volume fraction distributions within the acetylene/ air flames. $z=$ a) 50, b) 40 , c) 30 , d) 20 , and e) $10 \mathrm{~mm}$.

ties. ${ }^{19,20}$ This effect was evaluated by comparing results with and without acetone vapor present in the fuel, using the acetone purification train described by Hamins et al. ${ }^{28}$ The results illustrated in Fig. 4, with and without acetone present, indicate that the effect of acetone is small for present conditions.

\section{Flame Structure}

Detailed measurements of flame structure were undertaken at three air/fuel-stream velocity ratios for acetylene, at a pressure of $0.19 \mathrm{~atm}$, in order to gain a better understanding of the mechanism causing reduced soot emission tendencies at large $u_{a} / u_{f}$. The test conditions for the three flames are summarized in Table 1. The fuel flow rate (and thus, the burner Reynolds number) was kept constant for the three tests. For these conditions, the improved entrainment with increasing $u_{a} / u_{f}$ caused a reduction of luminous and stoichiometric flame lengths, as well as the characteristic residence times, for present conditions.
Figure 7 is an illustration of the soot volume fraction distributions within the three acetylene/air flames. The soot volume fraction distributions are illustrated at various heights above the burner exit, extending to $50 \mathrm{~mm}$, which is just before the luminous flame tip for $u_{a} / u_{f}=1.3$, and just after the luminous flame tip for the larger values of $u_{a} / u_{f}$. Based on species concentration measurements along the flame axis, it is estimated that the flame tip (represented by the stoichiometric condition reaching the flame axis) is at $z=77,60$, and $53 \mathrm{~mm}$ for $u_{a} / u_{f}=1.3,3.4$, and 6.3 , respectively, which is longer than the luminous flame lengths, e.g., $z=63,50$, and $43 \mathrm{~mm}$, respectively (see Table 1). Thus, the present non-soot-emitting flames actually completed soot oxidation before fuel-lean conditions were reached. This behavior is reasonable in view of recent observations that soot formation ends at fuel-rich conditions (at roughly a fuel-equivalence ratio of 1.4 where the concentrations of gaseous hydrocarbons become small) and that soot oxidation is significant for fuel-rich conditions, particularly for the region beyond the end of the soot formation region. $^{20-22}$

The effect of air/fuel velocity ratio on soot volume fraction distributions is quite dramatic in Fig. 7. Low values of $u_{a} / u_{r}$ yield a soot layer near the edge of the flame where rather large soot concentrations are reached. Increasing $u_{a} / u_{f}$, however, is seen to suppress the appearance of the soot layer, except at the very lowest position, $z=10 \mathrm{~mm}$. Values of soot volume fractions also are reduced along the axis as $u_{a} / u_{f}$ is increased. Taken together, this behavior clearly is consistent with reduced sooting tendencies as $u_{a} / u_{f}$ increases. As discussed later, this reduced sooting behavior comes about through two effects: 1) reduced residence times and 2 ) changed soot path directions with respect to the flame sheet.

Measured flow streamlines and the soot regions in the acetylene/air flames with $u_{a} / u_{f}=1.3$ and 6.3 are illustrated in Figs. 8 and 9 , respectively. It should be noted that flame shapes are distorted in these figures because dimensions in the radial direction have been expanded so that flow properties can be seen better. Reference conditions shown on the plots include the luminous flame boundary (which denotes the position of either the flame sheet that is indicated by the boundary of blue luminosity in the lower portion of the flame, or the limit of the soot-containing region that is indicated by the boundary of yellow luminosity in the upper portion of the flame), the limit of the soot-containing region in the lower portion of the flame (based on soot volume fraction measurements) and the locus of conditions where soot volume fractions reach a maximum in the radial direction (also based on soot volume fraction measurements). It should be recalled that the limit of the luminous boundary in the upper portions of the flame actually is reached before the flame sheet is reached (see Table 1).

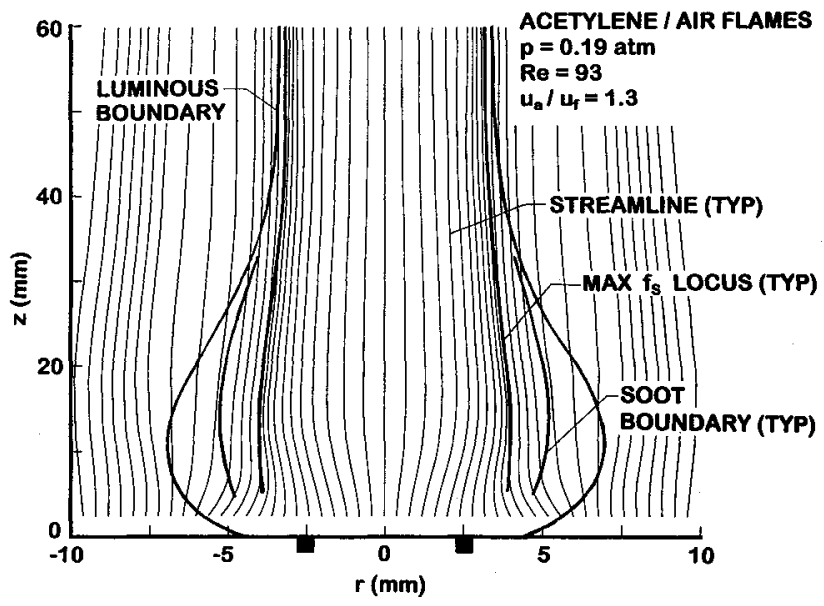

Fig. 8 Flow streamlines and flame and soot regions for the acetylene/air flame with an air/fuel velocity ratio of 1.3 . 


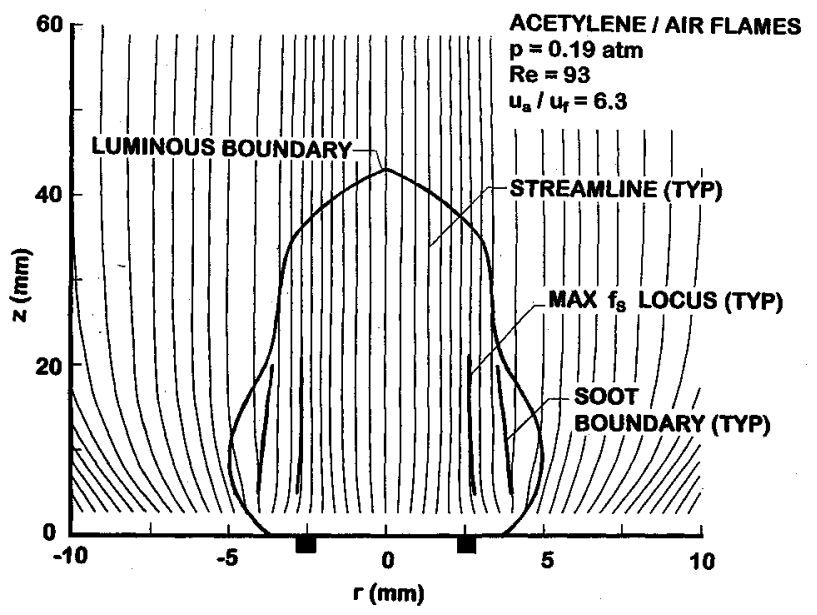

Fig. 9 Flow streamlines and flame and soot regions for the acetylene/air flame with an air/fuel velocity ratio of 6.3 .

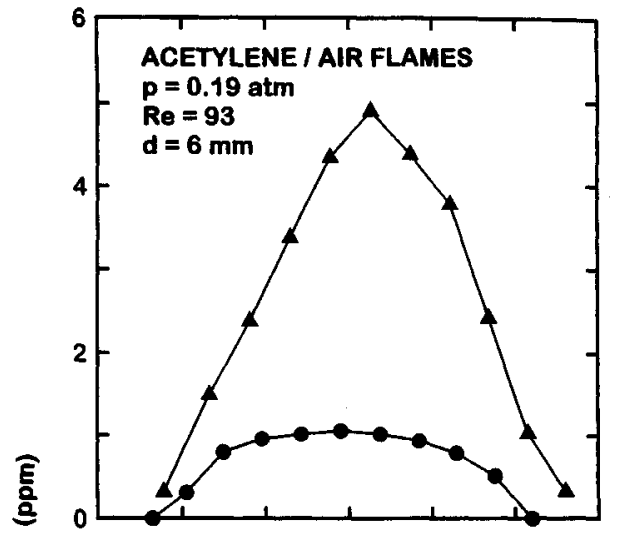

b)

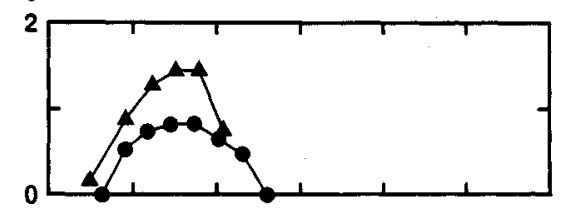

c)

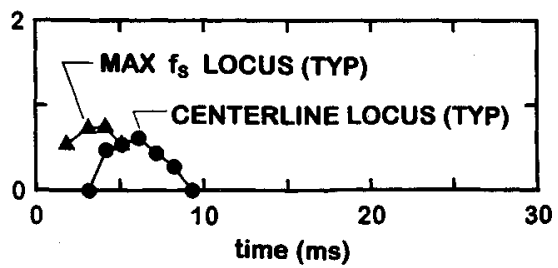

Fig. 10 Soot volume fractions as a function of residence time for soot paths within the acetylene/air flames. $u_{a} / u_{f}=$ a) 1.3, b) 3.4 , and c) 6.3 .

The results presented in Figs. 8 and 9 help clarify the difference between soot volume fractions for the paths through the maximum $f_{s}$ condition and the centerline as $u_{a} / u_{f}$ increases. In particular, for low $u_{a} / u_{f}$, the soot path line through the maximum $f_{s}$ condition actually starts near the flame sheet and then moves inward toward more fuel-rich conditions for a time; in contrast, the path line along the axis actually starts near the cool core of the flow and then moves monotonically toward fuel-lean conditions. At high $u_{a} / u_{f}$, however, all soot path lines start near the cool core and are drawn directly toward the flame sheet. Noting that soot nucleation rates are temperature-sensitive with a reasonable activation energy, ${ }^{20-22}$ suggests greater production of soot particles and more sites for soot growth for paths where nucleation begins near the flame sheet.

Effects of residence time and soot path on soot volume fractions are illustrated in Fig. 10 for the three acetylene flames.
These results consist of plots of soot volume fraction as a function of residence time along a soot path. Two paths are shown for each flame: 1) the path along the flame axis and 2) the path passing through the largest soot volume fraction observed in the flowfield. These results show that one effect of increasing $u_{a} / u_{f}$, while keeping $u_{f}$ constant, is to reduce the residence time for both paths. This causes a progressive reduction of soot volume fractions in accordance with the fastmixing argument that is widely accepted as a means of reducing sooting tendencies. ${ }^{1-3}$ An interesting feature about these results, however, is that residence times for the two soot paths are approximately the same for each value of $u_{a} / u_{f}$, even though soot volume fractions along the paths can be much larger for the path through the maximum soot volume fraction condition than for the path along the axis (particularly when $u_{a} / u_{f}$ is small). This latter effect is consistent with the entrainment argument discussed in connection with Fig. 1. Thus, soot nucleation beginning near the flame sheet yields a large number of soot nucleation sites, while subsequent inflow toward the fuel-rich region provides extended periods of time at conditions where soot growth is enhanced ${ }^{19}$; the net effect is much larger values of $f_{s}$ for this path than for the path along the axis, as seen in Fig. 10, when $u_{a} / u_{f}$ is small. These observations definitely support the advantages of large $u_{a} / u_{f}$ to reduce soot emissions.

An explanation of the effect of soot path on soot formation was sought by studying flame and soot structure properties for paths along the axis and through the maximum soot volume fraction condition. Thus, properties for paths along the axis and through the maximum $f_{s}$ position are illustrated in Figs. 11 and 12 , respectively; considering $u_{a} / u_{f}=1.3$, where soot concentration differences for the two paths differed substan-

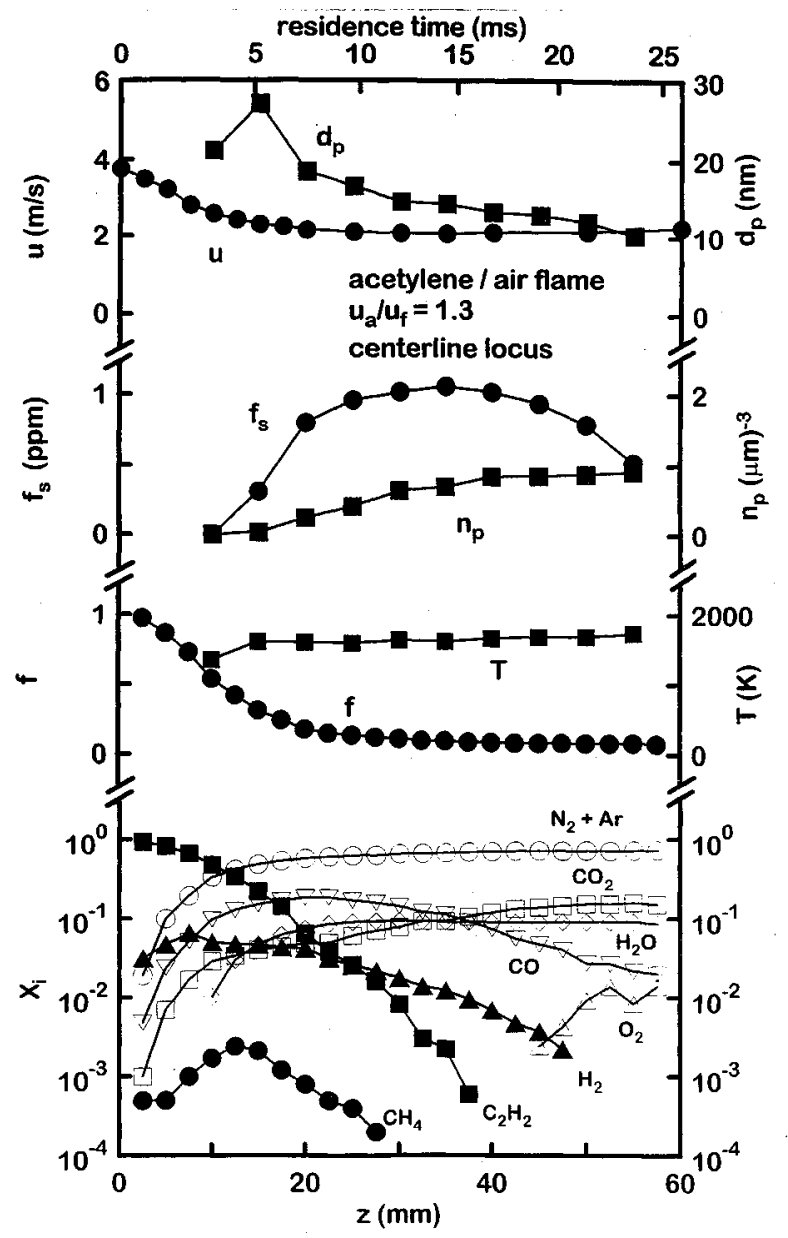

Fig. 11 Soot and flame properties along the axis of the acetylene/ air flame with an air/fuel velocity ratio of 1.3. 


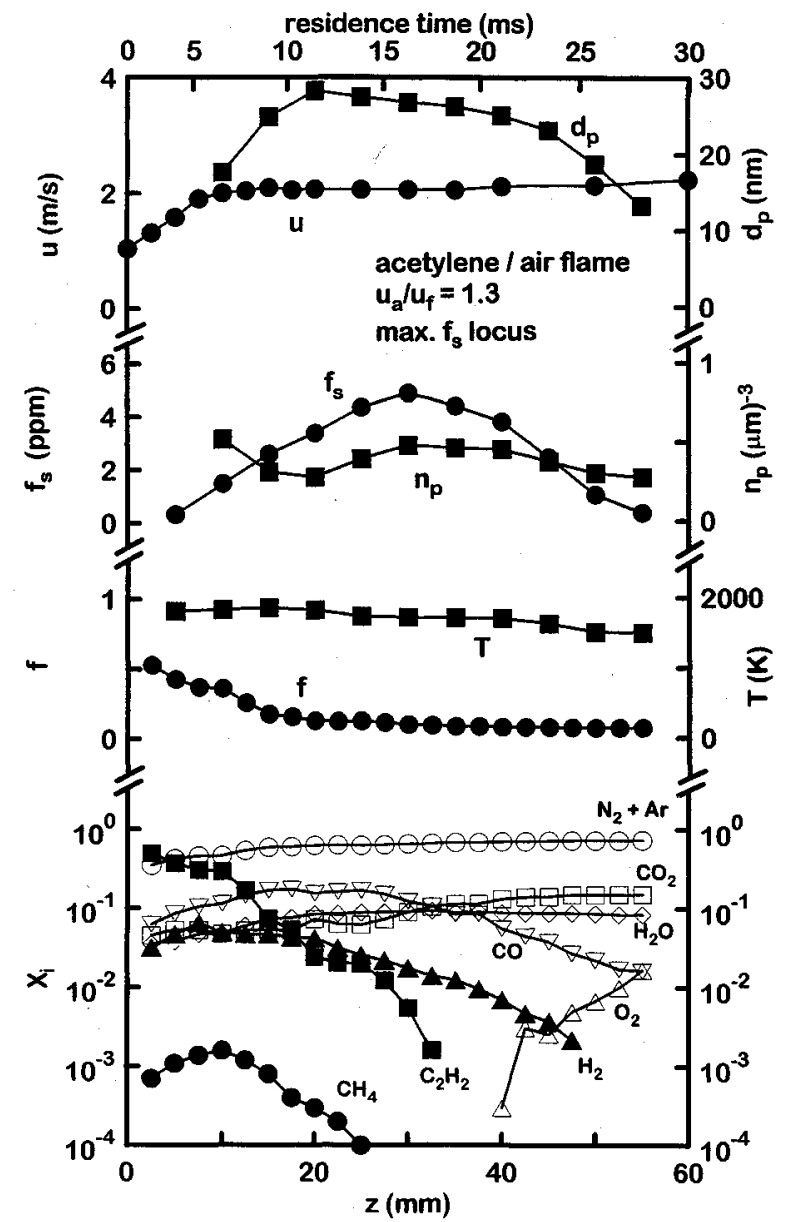

Fig. 12 Soot and flame properties along the axis through the maximum $f_{s}$ point of the acetylene/air flame with an air/fuel velocity ratio of 1.3 .

tially (see Fig. 10). Properties illustrated on the plots include $d_{p}, u, f_{s}, n_{p}, T, f$, and the mole fractions of major gas species, all plotted as a function of distance from the burner exit. Residence times from the burner exit, found by integrating the velocity measurements, are marked along the top of the plots as well.

Many of the features observed in Figs. 11 and 12 are similar to earlier observations along the axis of weakly buoyant acetylene/air diffusion flames ${ }^{20}$ : soot formation begins when temperatures exceed $1250 \mathrm{~K}$ and ends when hydrocarbon concentrations (mainly $\mathrm{C}_{2} \mathrm{H}_{2}$; recall that $\mathrm{C}_{2} \mathrm{H}_{4}, \mathrm{C}_{2} \mathrm{H}_{6}$, and $\mathrm{C}_{3} \mathrm{H}_{8}$ were sought, however, they were not found in significant concentrations) become small at a fuel-equivalence ratio of roughly 1.4; soot-oxidizing species (mainly $\mathrm{CO}_{2}$ and $\mathrm{H}_{2} \mathrm{O}$ ) are present throughout the soot-formation region, which implies that soot formation and oxidation occur simultaneously; the stronger temperature dependence of soot nucleation than soot growth implies that maximum primary soot particle diameters are reached before the end of the soot growth region; the concentrations of major gas species roughly approximate the generalized state relationships of soot-containing hydrocarbon diffusion flames ${ }^{29}$; and acetylene is the major hydrocarbon species present throughout the soot formation region. In view of present objectives, property differences between soot paths along the axis and through the maximum $f_{s}$ condition also are of major interest. First among these is the temperature distributions that gradually increase and decrease for paths along the axis and through the maximum $f_{s}$ condition, respectively; when combined with the temperature sensitivity of soot nucleation, ${ }^{20}$ this behavior implies a more rapid initial increase of $n_{p}$ for the path through the maximum $f_{s}$ condition, which provides more potential sites for soot growth early in the soot formation process. The next main difference involves velocity distributions, which decrease and increase for paths along the axis and through the maximum $f_{s}$ condition, respectively; as a result, residence times for soot growth are roughly $20 \%$ longer for the path through the maximum $f_{s}$ condition than for the path along the axis (roughy $13 \mathrm{~ms}$ as opposed to $11 \mathrm{~ms}$ ). Thus, the availability of more primary particles early in the growth period, and the slightly longer period of time available for growth, help explain the much larger soot concentrations for the path through the maximum $f_{s}$ condition than for the path along the axis seen in Fig. 10. Finally, the fact that increasing $u_{a} / u_{f}$ causes an increasing range of soot paths to approximate the behavior of soot paths along the axis then explains the corresponding progressive reduction of the tendency to soot, as exemplified by the laminar smoke-point results illustrated in Figs. 4-6.

\section{Conclusions}

The present experimental investigation considered the effect of air/fuel-stream velocity ratios on soot processes in laminar coflowing jet diffusion flames involving acetylene, propylene, and 1,3-butadiene burning in air. The major conclusions of the study are as follows:

1) Laminar smoke-point flame lengths and fuel flow rates were increased, with potential for soot emissions to be suppressed entirely, by increasing air/fuel-stream velocity ratios. These effects were most pronounced at low pressures where effects of buoyancy were minimized and initial air/fuel-stream velocity ratios are more representative of behavior for the entire flame for present test conditions.

2) Reduced soot concentrations within flames having increased air/fuel-stream velocity ratios involved the suppression of soot layers just on the fuel-rich side of the stoichiometric condition, and the predominance of soot paths where soot forms initially in the cool fuel-rich core of the flame and is drawn directly toward fuel-lean conditions.

3) Increased air/fuel-stream velocity ratios for a given fuel flow rate tended to reduce residence times, and thus, soot concentrations for present test conditions; however, the main effect of increased air/fuel-stream velocity ratios was to modify soot paths to enhance conditions where soot is drawn directly toward fuel-lean conditions, as discussed in 2 .

4) The present structure measurements suggest that soot concentrations are reduced along the paths where soot first nucleates in the cool core of the flame and is then drawn directly toward fuel-lean conditions, because nucleation rates initially are low due to low temperatures, which reduces the available sites for soot growth, and that the residence times available for soot growth also are reduced slightly, compared with soot paths that are associated with prominent soot layers that originate near the flame sheet.

Notably, similar observations about the importance of velocities along soot paths, relative to the flame sheet, on soot properties in diffusion flames have been recently reported by Sugiyama ${ }^{16}$ and Du and Axelbaum. ${ }^{17}$ The main difference between these studies and the present study is that the soot path velocity was controlled by air/fuel-stream velocity ratio in the present study and by the concentrations of the fuel and oxidizing streams in Refs. 16 and 17. Finally, the results of the present investigation strongly suggest that air atomization and film vaporization mainly reduce the sooting tendencies of diffusion flames by enhanced air/fuel-stream velocity ratios. Nevertheless, additional study will be required to show whether the present observations in gas-fueled laminar diffusion flames realistically represent behavior relevant to practical high-intensity spray combustion systems.

\section{Acknowledgments}

This research was supported by the Office of Naval Research Grant N00014-93-0321 under the technical manage- 
ment of G. D. Roy, and NASA Grant NAG3-1245 under the technical management of D. L. Urban of NASA Lewis Research Center.

\section{References}

${ }^{1}$ Glassman, I., "Soot Formation in Combustion Processes," 22nd Symposium (International) on Combustion, The Combustion Inst., Pittsburgh, PA, 1988, pp. 295-311.

${ }^{2}$ Haynes, B. S., and Wagner, H. G., "Soot Formation," Progress in Energy and Combustion Science, Vol. 7, No. 4, 1981, pp. 229273.

${ }^{3}$ Bahr, D. W., "Gas Turbine Engine Emission Abatement-Status and Needed Advancements," Gas Turbine Combustor Design Problems, edited by A. H. Lefebvre, Hemisphere, Washington, DC, 1979, pp. $205-223$.

${ }^{4}$ Sivathanu, Y. R., and Faeth, G. M., "Soot Volume Fractions in the Overfire Region of Turbulent Diffusion Flames," Combustion and Flame, Vol. 81, No. 2, 1990, pp. 133-149.

${ }^{5}$ Dobbins, R. A., and Megaridis, C. M., "Morphology of FlameGenerated Soot as Determined by Thermophoretic Sampling," Langmuir, Vol. 3, No. 2, 1987, pp. 254-259.

"Megaridis, C. M., and Dobbins, R. A., "Comparison of Soot Growth and Oxidation in Smoking and Nonsmoking Ethylene Diffusion Flames," Combustion Science and Technology, Vol. 66, No. 1, 1989, pp. $1-16$.

${ }^{7}$ Santoro, R. J., Semerjian, H. B., and Dobbins, R. A., "Soot Particle Measurements in Diffusion Flames," Combustion and Flame, Vol. 51, No. 2, 1983, pp. 203-218.

${ }^{8}$ Santoro, R. J., Yeh, T. T., Horvath, J. J., and Semerjian, H. G., "The Transport and Growth of Soot Particles in Laminar Diffusion Flames," Combustion Science and Technology, Vol. 53, No. 2, 1987. pp. 89-115.

${ }^{9}$ Kent, J. H., Jander, H., and Wagner, H. G., "Soot-Formation in a Laminar Diffusion Flame," 18th Symposium (International) on Combustion, The Combustion Inst., Pittsburgh, PA, 1980, pp. 1117-1124.

${ }^{10}$ Kent, J. H., and Wagner, H. G., "'Why Do Diffusion Flames Emit Smoke," Combustion Science and Technology, Vol. 41, No. 5, 1984, pp. $245-269$.

${ }^{11}$ Gore, J. P., and Faeth, G. M., "Structure and Spectral Radiation Properties of Turbulent Ethylene/Air Diffusion Flames," 21st Symposium (International) on Combustion, The Combustion Inst., Pittsburgh, PA, 1986, pp. 1521-1531.

${ }^{12}$ Gore, J. P., and Faeth, G. M., "Structure and Radiation Properties of Luminous Turbulent Acetylene/Air Diffusion Flames,' Journal of Heat Transfer, Vol. 110, No. 1, 1988, pp. 173-181.

${ }^{13}$ Sivathanu, Y. R., and Faeth, G. M., "Temperature/Soot Volume Fraction Correlations in the Fuel Rich Region of Buoyant Turbulent Diffusion Flames," Combustion and Flame, Vol. 81, No. 2, 1990, pp. $150-165$.

${ }^{14} \mathrm{Wu}, \mathrm{K} .-\mathrm{T}$., and Essenhigh, R. H., " Mapping and Structure of Inverse Diffusion Flames of Methane," 20th Symposium (International) on Combustion, The Combustion Inst., Pittsburgh, PA, 1984, pp. 1925-1932.

${ }^{15}$ Hussman, A. W., and Maybach, G. W., "The Film Vaporizer Combustor," SAE Transactions, Vol. 69, 1961, pp. 563-574.

${ }^{16}$ Sugiyama, G., "Nonluminous Diffusion Flame of Diluted Acetylene in Oxygen Enriched Air,"' 25th Symposium (International) on Combustion, The Combustion Inst., Pittsburgh, PA, 1994, pp. 601 608.

${ }^{17} \mathrm{Du}$, J., and Axelbaum, R. L., "The Effect of Flame Structure on Soot-Particle Inception in Diffusion Flames," Combustion and Flame, Vol. 100, No. 3, 1995, pp. 367-375.

${ }^{18}$ Schug, K. P., Manheimer-Timnat, Y., Yaccarino, P., and Glassman, I., "Sooting Behavior of Gaseous Hydrocarbon Diffusion Flames and the Influence of Additives," Combustion Science and Technology, Vol. 22, Nos. 5 and 6, 1980, pp. 235-250.

${ }^{19}$ Sunderland, P. B., Mortazavi, S., Faeth, G. M., and Urban, D. L., "Laminar Smoke-Points of Nonbuoyant Jet Diffusion Flames," Combustion and Flame, Vol. 96, No. 1, 1994, pp. 97-103.

${ }^{20}$ Sunderland, P. B., Köylü, Ü. Ö., and Faeth, G. M., "Soot Formation in Weakly-Buoyant Acetylene-Fueled Laminar Jet Diffusion Flames Burning in Air," Combustion and Flame, Vol. 100, Nos. 1 and 2, 1995, pp. 310-322.

${ }^{21}$ Lin, K.-C., Sunderland, P. B., and Faeth, G. M., "Soot Nucleation and Growth in Acetylene/Air Laminar Coflowing Jet Diffusion Flames," Combustion and Flame (to be published).

${ }^{22}$ Sunderland, P. B., and Faeth, G. M., "Soot in Hydrocarbon/Air Laminar Jet Diffusion Flames," Combustion and Flame (to be published).

${ }^{23}$ Law, C. K., and Faeth, G. M., "Opportunities and Challenges of Combustion in Microgravity," Progress in Energy and Combustion Science, Vol. 20, No. 1, 1994, pp. 65-113.

${ }^{24}$ Köylü, Ü. Ö., and Faeth, G. M., "Radiative Properties of FlameGenerated Soot," Journal of Heat Transfer, Vol. 115, No. 2, 1993, pp. $409-417$.

${ }^{25}$ Dalzell, W. H., and Sarofim, A. F., "Optical Constants of Soot and Their Application to Heat Flux Calculations," Journal of Heat Transfer, Vol. 91, No. 1, 1969, pp. 100-104.

${ }^{26}$ Köylü, Ü. Ö., and Faeth, G. M., "Optical Properties of Overfire Soot in Buoyant Turbulent Diffusion Flames at Long Residence Times," Journal of Heat Transfer, Vol. 116, No. 1, 1994, pp. 152159.

${ }^{27}$ Rosner, D. E., Mackowski, D. W., and Garcia-Ybarra, P., "Sizeand Structure-Insensitivity of the Thermophoretic Transport of Aggregated 'Soot' Particles in Gases,"' Combustion Science and Technology, Vol. 80, No. 1, 1991, pp. 87-101.

${ }^{28}$ Hamins, A., Gordon, A. S., Saito, K., and Seshadri, K., "Acetone Impurity in Acetylene from Tanks," Combustion and Science Technology, Vol. 45, No. 5, 1986, pp. 309, 310.

${ }^{29}$ Sivathanu, Y. R., and Faeth, G. M., "Generalized State Relationships for Scalar Properties in Nonpremixed Hydrocarbon/Air Flames,' Combustion and Flame, Vol. 82, Nos. 3 and 4, 1990, pp. 211-230. 